\title{
Anatomical Study of Nasal Septal Cartilage in Eastern Chinese
}

\author{
Kepeng $\mathrm{Hu}^{1,2}$, Haiting $\mathrm{Xu}^{1,2, *}$, Yean Zhang ${ }^{1,2}$, Zhouning $\operatorname{Lin}^{1,2}$, Yuanxia Chen ${ }^{1,2}$ \\ ${ }^{1}$ Department of Hand and Plastic Surgery, The Second Affiliated Hospital and Yuying Children's Hospital of Wenzhou Medical University, \\ Wenzhou, China \\ ${ }^{2}$ Department of Clinical medicine, Wenzhou Medical University, Wenzhou, China
}

Email address:

boatxu@163.com (Hai-ting Xu)

*Corresponding author

\section{To cite this article:}

Kepeng Hu, Haiting Xu, Yean Zhang, Zhouning Lin, Yuanxia Chen. Anatomical Study of Nasal Septal Cartilage in Eastern Chinese. Journal of Surgery. Vol. 7, No. 2, 2019, pp. 46-49. doi: 10.11648/j.js.20190702.15

Received: March 3, 2019; Accepted: April 12, 2019; Published: May 23, 2019

\begin{abstract}
Background: Asians tend to have foreshortened noses with more increased nostril show. In recent years, the nasal septal cartilage has been widely used in caudal septal advancement and nasal tip projection in East Asian. However, a relatively small quantity of less firm nasal cartilage was observed in East Asians compared with Caucasians and very few articles have been found dealing with septal cartilage anatomy of Chinese. Objective: The length, height, area, and thickness of nasal septal cartilage in 10 eastern Chinese were studied to provide anatomic data for the septorhinoplasty or harvesting of cartilage graft. Methods: The septal cartilages in 10 adult cadavers were anatomized and measured for their length, height, area, and thickness. Results: The average length and height of septal cartilage were respectively $2.83 \pm 0.47 \mathrm{~cm}$ and $2.41 \pm 0.39 \mathrm{~cm}$. The average area was $4.94 \pm 1.26 \mathrm{~cm}^{\wedge} 2$. The average thickness is $0.97 \pm 0.15 \mathrm{~mm}$, with the greatest thickness in region $\mathrm{b} 1.14 \pm 0.26 \mathrm{~mm}$, the least thickness in region e $(0.83 \pm 0.22) \mathrm{mm}$ and region a $(0.81 \pm 0.27) \mathrm{mm}$. Conclusion: The findings of this study reinforce the principle of key differences existing in the anatomic data of the septal cartilage between Asians and Caucasians.
\end{abstract}

Keywords: Nasal Septal Cartilage, Nasal Anatomy, Measurement, Cartilage Graft Thickness, Area

\section{Introduction}

In recent years, the nasal septal cartilage has been widely used in caudal septal advancement and tip projection in East Asian $[1,2]$. However, a relatively smaller quantity of and less firm nasal cartilage was observed in East Asians compared with Caucasians and very few articles have been found dealing with the length, height, area, and thickness of the septal cartilage of the Chinese. The purpose of this study was to precisely measure the length, height, area, and thickness of nasal septal cartilages in a cadaver series from East China.

\section{Materials and Methods}

Ten Chinese adult cadavers from East China were used (no obvious nasal septum deviation; including 7 males and 3 females, apparent ages ranging between 30 and 60 years old). Median incisions were made on the nose and the nasal septal cartilage was removed in its entirety. The excised septal cartilage was placed on grid paper; digital images were captured; the total area was calculated, along with the points of the greatest length and height (measured with a millimeter ruler, a digital caliper).

First, Points A (the junctional point of the septal cartilage and the nasal bone), B (the junctional point of the septal cartilage and the anterior nasal spine), and $\mathrm{C}$ (the junctional point of the septal cartilage, the perpendicular plate of ethmoid and the vomer) were defined. Then, two lines were drawn in the septal cartilage, an A-C line (height of the septal cartilage) and a B-C line (length of the septal cartilage) (Figure 1). Data were measured using a digital caliper (Hengliang Company, Shanghai, China). 

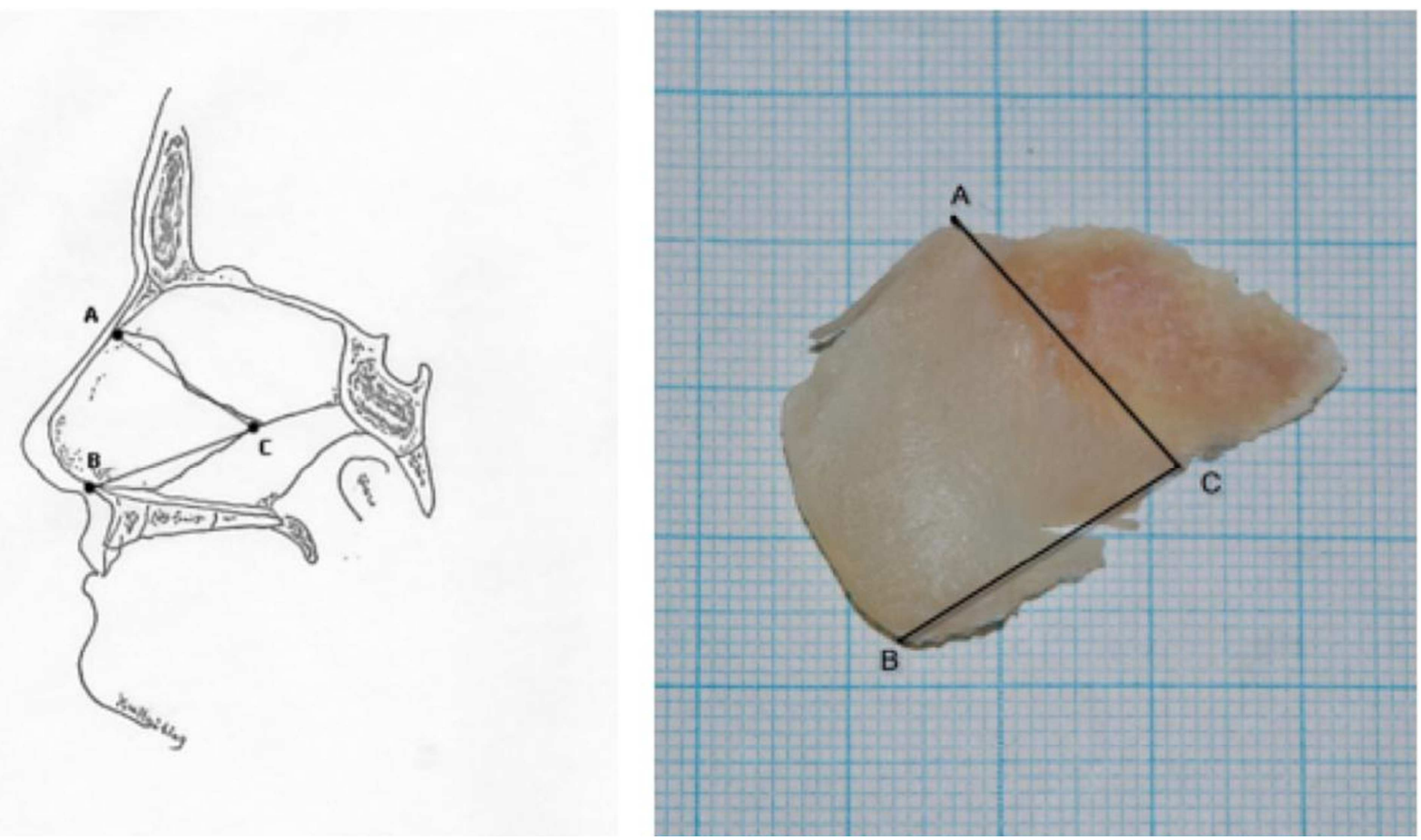

Figure 1. Measurement of the linear dimensions and areas of the septal cartilage. A, the junctional point of the septal cartilage and the nasal bone; $B$, the junctional point of the septal cartilage and the anterior nasal spine; $C$, the junctional point of 'the septal cartilage' and 'the perpendicular plate of ethmoid and vomer'. AC, height of the septal cartilage; $B C$, length of the septal cartilage.

Last, the whole septal cartilage was divided into five quadrants which were identified as a through e (Figure 2). The thickness of each part was measured at the midpoint of each quadrant with a digital caliper (Hengliang Company, Shanghai, China).

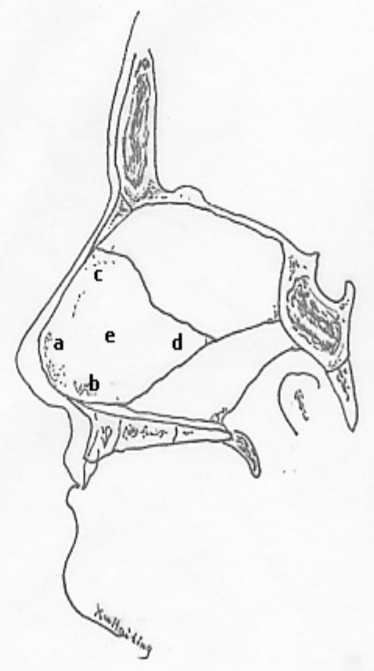

Figure 2. Measurement of the thickness of the septal cartilage: a, anterior septal angle; $b$, posterior septal angle and caudal septal base; $c$, dorsum; $d$, posterior region; e, central region.

Statistical analysis was performed using SAS 6.12 statistical software. Statistical significance was assumed at $\mathrm{P}<0.05$.

\section{Results}

The average length of septal cartilage was $2.83 \pm 0.47 \mathrm{~cm}$ (range, 2.16 to $3.45 \mathrm{~cm}$ ). The average height of septal cartilage was $2.41 \pm 0.39 \mathrm{~cm}$ (range, 1.78 to $3.21 \mathrm{~cm}$ ). The average septal area was $4.94 \pm 1.26 \mathrm{~cm}^{\wedge} 2$ (range, 3.15 to $7.26 \mathrm{~cm}^{\wedge} 2$ ). (Table 1 ). 
Table 1. The average area, length and height of septal cartilage.

\begin{tabular}{|c|c|c|c|c|c|}
\hline Variable & Mean \pm SD & 95\% Coefficient & Min & Max & $\mathrm{CV}$ \\
\hline Area $\left(\mathrm{cm}^{2}\right)$ & $4.94 \pm 1.26$ & $4.04 \sim 5.85$ & 7.26 & 3.15 & 0.26 \\
\hline Length $(\mathrm{cm})$ & $2.83 \pm 0.47$ & $2.49 \sim 3.17$ & 3.45 & 2.16 & 0.17 \\
\hline Height $(\mathrm{cm})$ & $2.41 \pm 0.39$ & $2.13 \sim 2.69$ & 3.21 & 1.78 & 0.16 \\
\hline
\end{tabular}

Mean septal thickness was measured in five parts and ranged from $0.81 \pm 0.27 \mathrm{~mm}$ to $1.14 \pm 0.26 \mathrm{~mm}$. There were no statistically significant differences $(\mathrm{p}>0.05)$. The average thickness is $0.97 \pm 0.15 \mathrm{~mm}$ (Table 2).

Table 2. The variable of septal cartilage thickness (m).

\begin{tabular}{ll}
\hline Quadrants & Mean \pm SD \\
\hline a & $0.81 \pm 0.27^{\Delta}$ \\
$\mathrm{b}$ & $1.14 \pm 0.26^{\Delta}$ \\
$\mathrm{c}$ & $1.09 \pm 0.37^{\Delta}$ \\
$\mathrm{d}$ & $1.00 \pm 0.24^{\Delta}$ \\
$\mathrm{e}$ & $0.83 \pm 0.22^{\Delta}$ \\
Mean & $0.97 \pm 0.15$ \\
\hline
\end{tabular}

$\mathrm{P}>0.05$.

\section{Discussion}

The placement of autogenous septal cartilage in Asian augmentation rhinoplasty and complex nasal reconstruction has also been extensively discussed [3-6]. However; studies regarding Asian septal morphology and its relation to cartilage graft choice are rare.

Hwang et al [7] evaluated septal cartilage in 14 adult Korean cadavers and found that The mean septal cartilage height was $2.99 \mathrm{~cm}$, and the mean length was $3.31 \mathrm{~cm}$. The septal base (anterior to the vomer) was the thickest area (range, 2.19 to $3.03 \mathrm{~mm}$ ), while the thinnest was the area superior to the septal base (range, 0.74 to $0.97 \mathrm{~mm}$ ). Jae Hee Kim et al [8] measured 152 Korean patients using 3D facial bone CT scanning and found the areas of the septal cartilage were $872.47 \pm 220.37 \mathrm{~mm}^{\wedge} 2$. Miles et al [9] found the average area of the cartilaginous septum was $817.2 \pm 167.2 \mathrm{~mm}^{\wedge} 2$, while the average height was $33.5 \mathrm{~mm}$ and the average width was $37.9 \mathrm{~mm}$. Mowlavi et al [10] identified the septal base as the thickest area $(2.7 \mathrm{~mm})$, the dorsal septum as having intermediate thickness $(2.0 \mathrm{~mm})$, and the central portion and the septal angle as the thinnest areas $(1.3$ and $1.2 \mathrm{~mm}$, respectively).

In this study, the average length of septal cartilage in the 10 Chinese cadavers was $2.83 \mathrm{~cm}$, while the average height was $2.41 \mathrm{~cm}$. The average area was $4.94 \mathrm{~cm}^{\wedge} 2$. The results were significantly smaller than those data in the previous articles, which was quite similar to the clinical observation of a less quantity of the Asian septal cartilage than Caucasian. The reason for the larger values of the septal cartilage in Korean studies is assumed to be the inclusion of the area which is easy to miss in the septal cartilage graft harvesting procedure, such as the septal tail they mentioned.

This study identified the posterior septal angle and caudal septal base as the thickest area $(1.14 \mathrm{~mm})$, the dorsum and the posterior region as having intermediate thickness (1.09 and $1.00 \mathrm{~mm}$, respectively), and the central region and anterior septal angle as the thinnest areas $(0.83$ and $0.81 \mathrm{~mm}$, respectively). There seems to be a difference over the thickest area between Korean findings of Hwang et al. and Chinese, because Korean septal cartilages were removed including a $1-\mathrm{cm}$ margin of the ethmoid and the vomer, which may lead to inaccurate results.

\section{Conclusion}

The findings of this study reinforce the principle of key differences existing in the anatomic data of the septal cartilage between Asians and Caucasians. The total area and average thickness of Asian septal cartilage is about $40 \%$ smaller than Caucasian. This has important surgical implications given the critical attention required during graft harvesting in order to maintain support of the noses in Asians.

\section{Acknowledgements}

The present study was supported by Wenzhou Public Welfare Science and Technoloy Project (Y20170451), Student Scientific Research Project of Wenzhou Medical University (wyx2016101016). The funders had no role in the design, execution, or writing of the study.

\section{References}

[1] Lee S H, Koo M G, Kang E T. Septal Cartilage/Ethmoid Bone Composite Graft: A New and Improved Method for the Correction Underdeveloped Nasal Septum in Patients with Short Noses [J]. Aesthetic Plastic Surgery, 2017, 41 (2): 1-7.

[2] Han S E, Han K, Choi J, et al. Modified Direct-Type Septal Extension Grafts: Their Stability and Usefulness in Asian Rhinoplasty [J]. Annals of Plastic Surgery, 2016, 78 (3): 1.

[3] Choi J Y, Kang I G, Javidnia H, et al. Complications of septal extension grafts in Asian patients [J]. Jama Facial Plast Surg, 2014, 16 (3): 169-175.

[4] Huang J, Liu Y. A modified technique of septal extension using a septal cartilage graft for short-nose rhinoplasty in Asians. [J]. Aesthetic Plast Surg, 2012, 36 (5): 1028-1038.

[5] Riedler K L, Shokrani A, Markarian A, et al. Age-related histologic and biochemical changes in auricular and septal cartilage [J]. The Laryngoscope, 2017.

[6] Bos E J, Pluemeekers M, Helder M, et al. Structural and Mechanical Comparison of Human Ear, Alar, and Septal Cartilage [J]. Plastic \& Reconstructive Surgery Global Open, 2018, 6 (1): 1.

[7] Hwang K, Huan F, Kim D J. Mapping thickness of nasal septal cartilage. [J]. Journal of Craniofacial Surgery, 2010, 21 (1): 243-4. 
[8] Kim J H, Jung D J, Kim H S, et al. Analysis of the Development of the Nasal Septum and Measurement of the Harvestable Septal Cartilage in Koreans Using Three-Dimensional Facial Bone Computed Tomography Scanning [J]. 2014, 41 (2): 163-170.

[9] Miles B A, Petrisor D, Kao H, et al. Anatomical variation of the nasal septum: Analysis of 57 cadaver specimens $[\mathrm{J}]$. Otolaryngology - Head and Neck Surgery, 2007, 136 (3): 362-368.

[10] Mowlavi A, Masouem S, Kalkanis J, et al. Septal cartilage defined: implications for nasal dynamics and rhinoplasty $[\mathrm{J}]$. Plastic \& Reconstructive Surgery, 2006, 117 (7): 2171-2174. 